\title{
RevistaHISTED ilitOn-line
}

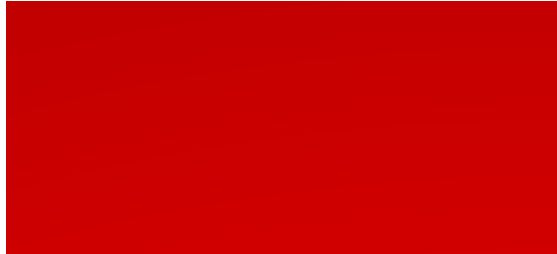

A Revista HISTEDBR On-line publica artigos resultantes de estudos e pesquisas científicas que abordam a educação como fenômeno social em sua vinculação com a reflexão histórica

Correspondência ao Autor Nome: Solange Pereira da Silva E-mail: solangesilva@ufpa.br Instituição: Universidade Federal do Pará, Brasil

Submetido: 22/02/2020 Aprovado: 19/04/2020 Publicado: 03/05/2021

doi> 10.20396/rho.v21i00.8658491 e-Location: e021015 ISSN: $1676-2584$

Como citar ABNT (NBR 6023):

SILVA, S. P. da. A regulação da formação continuada de

professores alfabetizadores no

Brasil. Revista HISTEDBR On-

line, v. 21, p. 1-22, abr. 2021. DOI:

10.20396/rho.v21i00.8658491.

Disponível em:

https://periodicos.sbu.unicamp.br/o js/index.php/histedbr/article/view/8 658491. Acesso em: 3 maio 2021.

\section{A REGULAÇÃO DA FORMAÇÃO CONTINUADA DE PROFESSORES ALFABETIZADORES NO BRASIL}

\author{
(9attes Solange Pereira da Silva* \\ Universidade Federal do Pará
}

\section{RESUMO}

O presente texto socializa as análises dos documentos produzidos pelos organismos internacionais, tais como Declaração Mundial de Educação para Todos (conferência de Jomtien em 1990), Declaração de Nova Délhi (1993), Relatório de Jaques Delors e o documento do Banco Mundial, com o objetivo de compreender a articulação com os documentos educacionais brasileiros, na perspectiva de apreender a regulação da formação continuada de professores alfabetizadores. A análise está fundamentada no materialismo histórico-dialético, construído a partir da literatura já produzida e da análise documental. Conclui-se que a formação continuada de professores encaminha-se para o esvaziamento da educação e formação humana destituída de qualquer sentido crítico pautada na lógica do conhecimento reduzido e da necessidade de revitalizar novos projetos de alfabetização de caráter cada vez mais excludentes.

PALAVRAS-CHAVE: Organismos internacionais. Educação brasileira. Formação continuada de professores alfabetizadores.

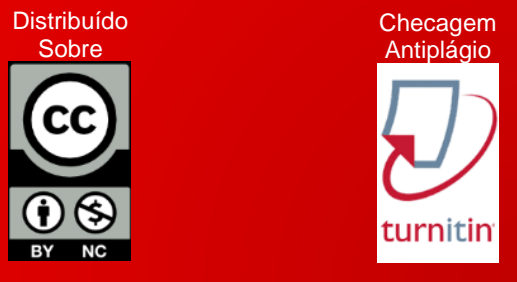




\title{
RevistallISTED ilitonntine \\ THE REGULATION OF THE CONTINUED TRAINING OF LITERACY TEACHERS IN BRAZIL
}

\begin{abstract}
This text socializes the analyzes of documents produced by international organizations, such as the World Declaration on Education for All (Jomtien conference in 1990), the New Delhi Declaration (1993), the Jacques Delors Report, and the World Bank document, with the objective of understanding the articulation with the Brazilian educational documents, in the perspective of apprehending the regulation of the continuing education of literacy teachers. The analysis is based on historical-dialectical materialism, built from the literature already produced and from documentary analysis. It is concluded that the continuing education of teachers is directed towards the emptying of education and human formation devoid of any critical sense based on the logic of reduced knowledge and the need to revitalize new literacy projects of an increasingly exclusive nature.
\end{abstract}

Keywords: International organizations. Brazilian education. Continuing education of literacy teachers.

\section{EL REGLAMENTO DE LA ENTRENAMIENTO CONTINUA DE LOS PROFESORES DE LITERACY EN BRASIL}

\section{Resumen}

Este texto socializa el análisis de documentos producidos por organizaciones internacionales, como: Declaración Mundial sobre Educación para Todos (Conferencia de Jomtien en 1990), Declaración de Nueva Delhi (1993), Informe Jaques Delors y documento del Banco Mundial, para comprender la articulación con los documentos educativos brasileños, en la perspectiva de aprehender la génesis de la educación continua de los profesores de alfabetización. El análisis se basa en el materialismo dialéctico histórico, construido a partir de la literatura ya producida y el análisis documental. Se concluye que la educación continua de los docentes conduce al vaciamiento de la educación y la formación humana sin ningún sentido crítico basado en la lógica del conocimiento reducido y la necesidad de revitalizar nuevos proyectos de alfabetización de una naturaleza cada vez más exclusiva.

Palabras clave: Organizaciones internacionales. Educación brasileña. Educación continúa de los profesores de alfabetización. 


\section{Revista HISTED ilitOn-line}

\section{INTRODUÇÃO}

"Começar pelas palavras talvez não seja coisa vã. As relações entre fenômenos deixam marcas no corpo da linguagem [...]", já afirmava Alfredo Bosi (1992, p. 11). No Dicionário de Língua Portuguesa on-line, "regulação" significa "[...] o ato de regular, de estabelecer normas: regulação do valor do salário. Ação de ajustar, de afinar; afinação, ajustamento." (DICIONÁRIO..., 2020). No campo da Educação, a palavra "regulação" exerce a função de controlar as políticas educacionais desenvolvidas pelo Estado, que, guiadas pelas agências dos organismos multilaterais, ajustam elementos inspirados em modelos de currículos reflexivos direcionados para a formação inicial e continuada de professores, pautadas na lógica da competência e habilidades cognitivas, priorizando conhecimentos específicos, tais como Língua Portuguesa e Matemática, ou seja, leitura, escrita, raciocínio lógico e cálculo matemático.

Historicamente, a formação continuada de professores adquiriu sustentação teórica a partir de 1930 com o advento da Escola Nova com as perspectivas do "aprender a aprender"; incorporou as concepções pedagógicas tecnicistas a partir dos anos de 1970, que orientava a formação continuada de professores para o cumprimento de tarefas. No final dos anos de 1980, assiste-se ao deslocamento do significado nos vocabulários inseridos no contexto educacional das diferentes políticas de formação continuada, como "reciclagem", “capacitação", "treinamento", "capacitação" e "aperfeiçoamento".

A partir do final dos anos de 1990, foram constituídos novos vocabulários direcionados para a formação continuada de professores, tais como "professor pesquisador", "professor reflexivo", "professor alfabetizador", objetivando a superação do fracasso escolar nas séries iniciais, durante o processo de alfabetização.

A partir desses esclarecimentos, considera-se, neste artigo, a trajetória inquirida no cenário brasileiro acerca das políticas destinadas para a formação continuada de professores, regulada por leis, pareceres e decretos, programas de alfabetização e avaliações externas. Nesse sentido, o presente texto socializa as análises dos documentos produzidos pelos organismos internacionais, objetivando compreender a articulação desses documentos com os documentos educacionais brasileiros e o processo de regulação da formação continuada de professores alfabetizadores no Brasil.

O trabalho está fundamentado no materialismo histórico-dialético, dado seu papel ontológico ligado à própria constituição do ser social, inseparável da história e da produção da vida material, entendendo, a partir de Marx, que os homens constroem sua história, mas não da maneira como pensa ou idealiza, e, sim, de acordo com as determinações históricas constituídas dentro da sociedade em que estão inseridos.

Dessa forma, o artigo está organizado com esta Introdução, duas seções e as Considerações Finais. Na primeira seção, apresenta-se o contexto histórico em que foram produzidos os documentos dos organismos internacionais e sua presença nos documentos e 


\section{RevistaHISTED Billontine}

leis educacionais brasileiras na constituição da política de professores alfabetizadores no Brasil. Na segunda, apresenta-se a regulação do professor alfabetizador no Brasil e as principais implicações dessas políticas para a constituição da formação continuada de professores. Por fim, expõe as Considerações Finais, sinalizando algumas perspectivas de enfrentamento no que diz respeito à formação continuada de professores alfabetizadores.

\section{A PRESENÇA DOS ORGANISMOS INTERNACIONAIS NOS DOCUMENTOS E LEIS EDUCACIONAIS BRASILEIRAS}

A retomada da Organização das Nações Unidas para Educação, a Ciência e a Cultura (UNESCO) acerca dos problemas da alfabetização global direcionada para as séries iniciais, a partir dos anos de 1990, iniciou-se com a Conferência Mundial de Educação para Todos, realizada em Jotiem, na Tailândia, no ano de 1990, financiada pelo Fundo das Nações Unidas para a Infância (UNICEF), UNESCO e o Programa das Nações Unidas para o Desenvolvimento (PNUD), patrocinada pelo Banco Mundial (BM), com a participação de 155 governos, nos quais se fizeram presentes “[...] agências internacionais, organismos não governamentais, associações profissionais e personalidades do âmbito educativo, e firmaram compromisso em garantir a educação básica de qualidade para crianças, jovem e adulta." (SHIROMA; MORAES; EVANGELISTA, 2011, p. 48).

Tomando como referência o final dos anos de 1950, Gontijo (2014, p. 18) explica que a UNESCO defendia uma:

[...] educação [...] pautada na perspectiva do desenvolvimento "econômico" fundada na teoria do capital humano, e a alfabetização não poderia ser considerada um fim em si mesmo, mas devia preparar o homem para desempenhar um papel social, cívico e econômico na sociedade, rompendo com a ideia que alfabetização se reduza ao ensino de leitura e escrita.

Britto (2007, p. 20) destaca que a UNESCO “[...] estabeleceu um padrão internacional para estatística em educação e políticas educacionais e propôs uma nova definição do conceito de alfabetização." De acordo com esse novo conceito, quem soubesse ler e escrever frases simples estava apto para viver na sociedade letrada, estabelecendo, assim, em âmbito global, o mínimo de leitura e de escrita, para as novas gerações saberem se movimentar de forma reduzida dentro das sociedades industrializadas.

No documento final da Conferência Mundial de Educação, conhecido como "Declaração Mundial sobre Educação para Todos: Satisfação das Necessidades Básicas de Aprendizagem", verifica-se, claramente, a introdução de um novo conceito de educação básica, recomendada pela NEBAS (Necessidades Básicas de Aprendizagens) para avançar no Ensino Fundamental e Médio, presumida pelo acesso “[...] a leitura e a escrita, a expressão 


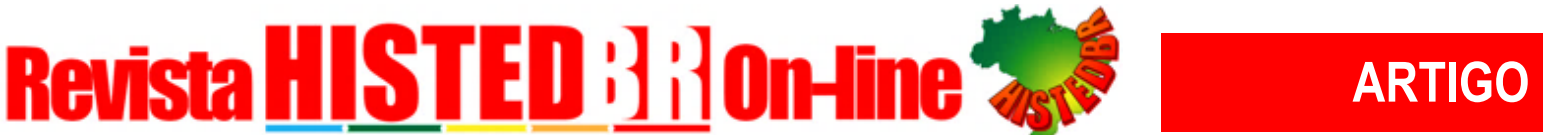

oral, o cálculo e a solução de problemas, habilidades essenciais para jovens e adultos, acesso ao conhecimento e habilidades através da mídia de massa." (UNESCO, 1990, p. 1).

A centralidade do pacto consensual entre os países signatários ao final da Conferência Mundial de Educação para Todos assumiam a universalização do acesso à Educação Fundamental como condição fundamental de solucionar a questão da pobreza, bem como promover sua equidade. Já estava dito no Documento que a educação básica seria prioridade para promoção dos "[...] direitos humanos comumente aceitos [...]", (UNESCO, 1990, p. 1), ao passo que a continuidade para o ensino superior já se enquadrava fora do Direito Público.

Tais questões, definidas como prioridade pelo BM, podem ser confirmadas na publicação denominada de Prioridades y estratégias para la educación: Examen del Banco Mundial (1995a, p. 12, tradução nossa):

Educação primária de boa qualidade para todas as crianças como primeira prioridade das despesas públicas na educação de todos os países. Melhor acesso ao ensino secundário geral, de boa qualidade (inicialmente de primeiro ciclo e mais tarde também superior) como segunda prioridade, uma vez todas as crianças que recebem educação primária de boa qualidade. Eficiente das despesas públicas a nível das escolas e instituições. Sustentabilidade fiscal também requer constante projeção do impacto das despesas públicas e um esforço sustentado para garantir que os planos mecanismos de financiamento.

Em tempo de globalização e neoliberalismo econômico, a atuação conjunta da UNESCO, do BM e da OCDE (Organização para a Cooperação e Desenvolvimento Econômico), nas formulações de propostas para orientação das políticas educacionais, ultrapassaram as fronteiras internacionais, pautadas na valorização de disciplinas, tais como Matemática, Língua Portuguesa, seguindo a lógica estabelecida pelo corpus de conhecimento medido pelos resultados de avaliações internacionais de estudantes, tais como o Programa Internacional de Avaliação de Estudante (PISA).

As avaliações do PISA formuladas pela OCDE, ao ser descritas e confrontadas entre diferentes continentes, transformam o processo de aprendizagem dos alunos em resultados estatísticos que determinam o fracasso ou avanço educacional, em que os professores são peças fundamentais para conduzir a eficácia ou a ineficiência desses resultados, tornando mais perversa ainda essa lógica, pois foram concebidas com objetivos de promover "[...] a redução do sistema educacional ao ensino elementar e atende às exigências dos organismos internacionais de limitar os gastos educacionais." (SEGUNDO; JIMENEZ, 2015, p. 49).

De acordo com Mølstad, Pettersson e Prøitz (2019, p. 22), “[...] a OCDE moldou um raciocínio sobre políticas internacionais por meio de suas classificações, publicações, avaliações de conhecimento internacional e revisões de políticas temáticas e nacionais." Nesse sentido, os países-membros tornaram-se gerenciadores de plano e programa de 


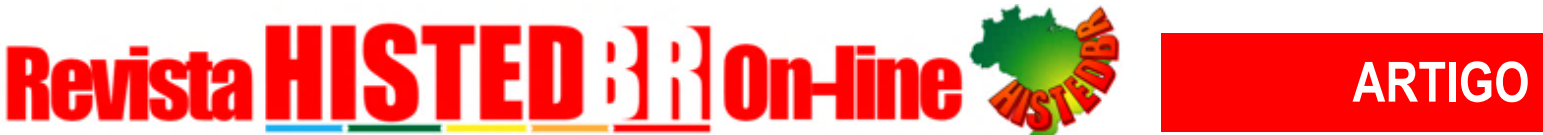

avaliação, projetado pela OCDE para a educação; e mesmo os países que não são membros, assim como o Brasil, seguiram em parte essas orientações.

Verifica-se a mesma relação da UNESCO através da Conferência de Jomtien, em 1990, que aprovou a Declaração de Jomtien para "[...] satisfazer as necessidades básicas de aprendizagem [...]” (UNESCO, 1990, p. 1), editando, assim, os rumos para a educação básica, articulando a ideia de adaptação da educação para atendimento da lógica economicista, e os conhecimentos centralizados em competências básicas para aquisição da leitura, da escrita e do cálculo, pautados na pedagogia da eficiência e dos resultados das avaliações externas.

O processo de "[...] ampliar os meios de e o raio de ação da educação básica [...]" (UNESCO, 1990), previsto no Art. 5 da Declaração, está articulado às estratégias desenvolvidas pelo BM, que vêm orientando a participação das famílias, das comunidades nos programas institucionais, inserindo-se nesse contexto a lógica da gestão da educação básica compartilhada com todos os segmentos da sociedade, inclusive com o discurso de "democratizar" os espaços da escola, distribuindo tarefas de cunho pedagógico e financeiro para colaboradores, amigos da escola e empresários, para "[...] assumirem responsabilidades, com as aprendizagens de todos os estudantes para que possam adquirir o saber e as competências necessários para uma vida feliz e produtiva." (BANCO MUNDIAL, 2011, p. $3)$.

Segundo o Documento, um dos requisitos básicos para avançar no processo de universalidade da educação básica, principalmente nas séries iniciais, previsto no artigo 7, é o "fortalecimento das alianças", no qual a busca de apoio e colaboração da sociedade civil, das empresas, seria considerado uma nova forma de se fazer educação, pois as "[...] alianças efetivas contribuem significativamente para o planejamento, implementação, administração e avaliação dos programas de educação básica." (UNESCO 1990, p. 6).

Após a Conferência de Jomtien (1990), registra-se o novo encontro em Nova Délhi, no ano de 1993, com a participação de nove países mais populosos do mundo, tais como Indonésia, China, Bangladesh, Brasil, Egito, México, Nigéria, Paquistão e Índia, objetivando a realização do balanço dos compromissos firmados em Jomtien. Nesse encontro, foi estabelecido, até o ano de 2000, o cumprimento das metas de universalização da educação básica. Convocaram, segundo o Documento, todas as "[...] instituições financeiras para reconhecer a educação como investimento crítico e isento de textos preestabelecidos para que os países pudessem sustentar seu desenvolvimento econômico." (UNESCO, 1993, p. 2).

Dentre as metas rediscutidas e redefinidas pelos países participantes, chama-se a atenção a redação dos seguintes itens:

2.3 - Ampliação da oferta de vagas na educação elementar e nos programas de alfabetização de adultos, em articulação com a melhoria da qualidade dos programas de educação básica, do treinamento e condições de trabalho do magistério, como da implantação de diferentes reformas no âmbito dos 


\title{
Revista HISTED iHilOn-line
}

ARTIGO

sistemas educacionais. 2.4 - Os conteúdos e métodos de educação precisam ser desenvolvidos para servir às necessidades básicas de aprendizagem dos indivíduos e das sociedades, proporcionando-lhes o poder de enfrentar seus problemas mais urgentes - combate à pobreza, aumento da produtividade, melhora das condições de vida e proteção ao meio ambiente. (UNESCO, 1993, p. 1).

Esses documentos inserem-se como orientadores da educação dos países em escala mundial, e trazem em suas proposições perspectivas teóricas pautadas nas competências e habilidades traduzidas no ensino de microprocedimentos dentro dos cursos de formação, seja inicial ou continuada, retirando qualquer possibilidade de formação crítica e de luta pela democratização da escola pública.

Na mesma lógica, o Fórum Mundial de Educação, realizado em Dakar, Senegal, no período de 26 a 28 de abril de 2000, reafirmou a visão da Declaração Mundial de Educação Para Todos (UNESCO, 1990, p. 1), "[...] de que toda criança, jovem e adulto têm o direito humano de se beneficiar de uma educação que satisfaça suas necessidades básicas de aprendizagem [...]”; esses pressupostos apoiam-se em uma concepção político-econômica de cunho neoliberal, ou seja, "[...] a alfabetização é o elemento que articula essas metas. [...] o que será assegurado por meio da mensuração de resultados, principalmente em relação à alfabetização, ao cálculo e às habilidades essenciais para a vida.” (GONTIJO 2012, p. 606).

Os efeitos da Conferência de Jomtien (1990) e Nova Délhi (1993) se refletiram nas políticas brasileiras, na produção ideológica de autores ligados ao MEC (Ministério da Educação), para explicar os problemas sociais, propor estratégias educacionais, enfrentamento do desemprego, geração de renda, diminuição da pobreza de modo geral, em conformidade com a Declaração de Nova Délhi, que recomendava "[...] [que] uma parcela crescente dos recursos nacionais e comunitários seja canalizada à educação básica e melhoria do gerenciamento dos recursos educacionais agora disponíveis." (UNESCO, 1993, p. 1).

Verifica-se forte influência das conferências, na construção do Plano Decenal para Todos (BRASIL, 1993), a partir do Governo Itamar Franco (29 dez. 1992 -1º jan. 1995), quando exibiu no Documento o diagnóstico da educação brasileira e seus vários obstáculos para o desenvolvimento da universalização da educação básica, tais como:

\begin{abstract}
A baixa produtividade do sistema, evidenciada pelas perdas observadas, por repetência e evasão, em sucessivas gerações escolares. Nível insatisfatório de qualidade do ensino, expresso em modestos índices de desempenho escolar; práticas de avaliação do desempenho escolar inadequadas, incapazes de proporcionar uma visão globalizada das dificuldades, e ausência de metodologias e processos adequados [...]. (BRASIL, 1993, p. 31).
\end{abstract}

A solução para este quadro crítico, sugerido pelo Documento, articulava a "[...] realização de planos e projetos de avaliação externa [...]”, para monitoramento das ações, pois, "[...] aplicados em âmbito nacional, estadual e local, previa as variações de condições 


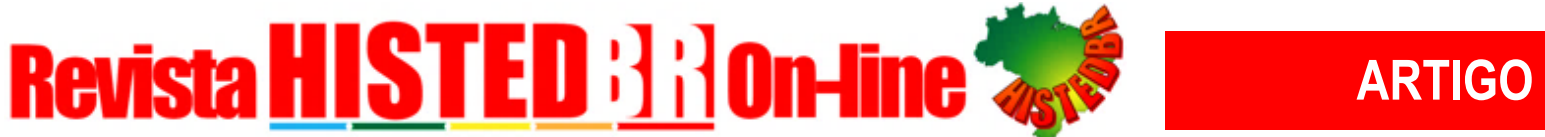

e circunstâncias as quais se encontravam a educação [...]", para obtenção do progresso na consecução das metas, conforme sugerido pela Declaração de Jomtien. (UNESCO, 1990, p. 7). A proposta de aprendizagem, para ser desenvolvida nos vários ciclos, etapa e/ou séries da educação básica, deveria estar centrada, segundo o Plano Decenal, "[...] no domínio cognitivo, incluindo habilidades de comunicação, expressão oral e escrita, cálculo e raciocínio lógico, melhoria do livro didático e formação de professores." (BRASIL, 1993, p. $31)$.

A lógica de substituição dos conhecimentos universais por conhecimentos imediatos, de acordo com os interesses dos educandos, foi retomada através dos discursos escolanovista, propostos pelos reformuladores da Escola Nova da pedagogia do "[...] aprender a aprender [...]”, que, na prática, “[...] significava adquirir a capacidade de buscar conhecimentos por si mesmo, de adaptar-se a uma sociedade que era compreendida como um organismo em que cada indivíduo tinha um papel determinado [...]". (SAVIANI, 2013, p. 432).

No entendimento de Saviani (2013), configuram-se na atualidade as bases didáticas pedagógicas denominadas de "neoescolanovismo", articuladas às novas concepções pedagógicas adotadas nos projetos e programas educacionais dos organismos internacionais desde o final de 1970, visando o atendimento das novas exigências de reestruturação do capital provocado pela crise econômica mundial, em que a educação, para o " [...] aprender a aprender na atualidade [...] liga-se à necessidade de constante atualização exigida pela necessidade de ampliar a esfera da empregabilidade." (SAVIANI, 2013, p. 432), ou seja, a adequação ao conhecimento das novas exigências do mercado frente ao processo de readaptação dos sujeitos aos novos postos de trabalhos, tais como as relações flexibilizadas, acordos coletivos entre patrão e empregado, retirados de direitos trabalhistas.

Essa visão, amplamente propagada em escala mundial, tornou-se a principal orientação do Plano Decenal, inaugurando assim o processo de implantação da educação e formação humana, inspirado pelo discurso neoliberal ${ }^{1}$, da qualidade total, pautado na lógica do enxugamento das contas públicas, justificado pelos discursos da extinção de conteúdos que não estivessem aplicabilidade em sala de aula, determinando por um currículo mínimo e prático, vinculada as avaliações externas.

Nesse sentido, a tese defendida Guiomar de Mello, nos anos de 1990, após revisitar as diversas proposições influentes dos diversos países, como das escolas asiáticas, da tradição inglesa e na tradição norte-americana, era de que:

[...] A melhoria da eficácia da escola requer mudanças na cultura da instituição que, segundo a hipótese apresentada neste trabalho, implicam em saber ensinar. [...] A eficácia, portanto, ainda que se caracterize por mudanças dentro da escola, para as quais parceria, consenso, objetivos compartilhados, permanente avaliação do aluno e autoavaliação da escola são indispensáveis, depende também, em larga medida, de induções externas. Entretanto, induzir não é prescrever e sim criar condições e 


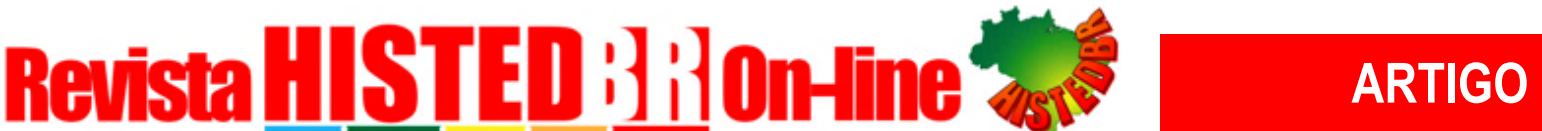

estímulos que favoreçam o aparecimento da cultura do sucesso que supostamente seria pré-requisito para melhorar a eficácia. (MELLO, 1994, p. 35, grifos do autor).

O sabe ensinar, a eficácia, avaliação em larga medida de indução externa foram os pontos-chave na concepção da autora para a melhoria da educação e atendimento dos desígnios da universalização do ensino básico. Favorável ao um sistema de avaliação sistemático e contínuo no país, as teses de Mello (1994) advogavam que o investimento na formação de professores deveria estar centrado nessa lógica. O caminho percorrido pela autora estava em consonância com as políticas de avaliação adotadas pela OCDE e o BM, que sustentavam que para avançar na educação brasileira deveria ser implementado o sistema de avaliação:

(i) [...] um sistema de avaliação que permita realizar diagnósticos e aferir resultados em termos do progresso da aprendizagem dos conteúdos básicos; (ii) adotar uma sistemática de financiamento e transferência de recursos que vise a aumentar os montantes destinados às escolas à equalização das condições[...]; (iii) estabelecer os conteúdos curriculares básicos por série e grau de ensino e, por consequência, as normas gerais para formação de professores, avaliando esta última também por resultados; [...]. (MELLO, 1991, p. 32).

Outro documento que influenciou fortemente na reforma da educação brasileira foi o relatório da UNESCO, elaborado pela Comissão Internacional sobre Educação para o Século XXI, no período de 1993 a 1996. Coordenado pelo economista Jacques Delors, tinha por objetivo orientar as necessidades da formação humana para as novas exigências do novo mercado político e econômico. Este Documento foi publicado no Brasil no ano de $1998 \mathrm{com}$ o título Educação: um tesouro a descobrir, delineando, no Capítulo V, "Os quatro pilares da educação”, questões basilares para a educação, conforme destacado na síntese do Quadro 1.

Quadro 1 - "Os quatro pilares da Educação"

(continua)

\begin{tabular}{|c|l|}
\hline Os pilares & \multicolumn{1}{c|}{ As recomendações } \\
\hline $\begin{array}{c}\text { "Aprender a } \\
\text { conhecer" }\end{array}$ & $\begin{array}{l}\text { "Combinando uma cultura geral, suficientemente vasta, com a possibilidade de } \\
\text { trabalhar em profundidade um pequeno número de matérias. O que também } \\
\text { significa: aprender a aprender, para beneficiar-se das oportunidades oferecidas } \\
\text { pela educação ao longo de toda a vida." }\end{array}$ \\
\hline $\begin{array}{c}\text { "Aprender a } \\
\text { fazer" }\end{array}$ & $\begin{array}{l}\text { "A fim de adquirir, não somente uma qualificação profissional mas, de uma } \\
\text { maneira mais ampla, competências que tornem a pessoa apta a enfrentar } \\
\text { numerosas situações e a trabalhar em equipe. Mas também aprender a fazer, no } \\
\text { âmbito das diversas experiências sociais ou de trabalho que se oferecem aos } \\
\text { jovens e adolescentes [...]." }\end{array}$ \\
\hline $\begin{array}{c}\text { "Aprender a a } \\
\text { viver juntos" }\end{array}$ & $\begin{array}{l}\text { "Desenvolvendo a compreensão do outro e a percepção das interdependências } \\
\text { - realizar projetos comuns e preparar-se para gerir conflitos - no respeito pelos } \\
\text { valores do pluralismo, da compreensão mútua e da paz." }\end{array}$ \\
\hline
\end{tabular}




\section{Revista HIISTED Hiitontine}

ARTIGO

Quadro 1 - "Os quatro pilares da Educação"

(conclusão)

\begin{tabular}{|c|l|}
\hline "Aprender & $\begin{array}{l}\text { "Para melhor desenvolver a sua personalidade e estar à altura de agir com cada } \\
\text { vez maior capacidade de autonomia, de discernimento e de responsabilidade } \\
\text { pessoal. Para isso, não negligenciar na educação nenhuma das potencialidades de } \\
\text { cada indivíduo: memória, raciocínio, sentido estético, capacidades físicas, aptidão } \\
\text { para comunicar-se." }\end{array}$ \\
\hline
\end{tabular}

Fonte: Delors et al. (2001, p. 89-101).

O Relatório Delors prosseguiu a tese defendida pelas Conferências de Jomtien e Nova Délhi, ou seja, da Educação como perspectiva de desenvolvimento econômico e social. Como se fosse um chamado "messiânico", conclamou a educação para a remissão dos problemas mundiais, através da união, solidariedade entre os grupos empresariais, organismos não governamentais, instituições educacionais, bem como todos aqueles que acreditam na possível articulação da sociedade capitalista para encontrar soluções que evitem a expansão dos conflitos mundiais, e estabeleça a harmonia entre os povos.

Sustentou-se a ideia de que um sistema educacional se faz com a participação de todos da sociedade, e reproduziu a falácia da democratização compartilhada no interior das escolas, na qual, segundo o Relatório, “[...] supõe a colaboração dos pais na definição do percurso escolar dos filhos e a ajuda às famílias mais pobres [...]”. (DELORS et al., 2001, p. 54). A grande preocupação dos colaboradores do Relatório era propor diretrizes teóricas (Quadro 1) para a educação que tivessem vinculadas ao processo de reestruturação da sustentabilidade econômica dos países pobres; e neste caso, a educação foi mais uma vez apontada como perspectiva de mobilização social, com viés ideológico da sociedade do conhecimento a partir dos quatros pilares apresentados, tais como: "Aprender a conhecer", "Aprender a fazer", "Aprender a viver juntos, aprender a viver com os outros" e "Aprender a ser".

Os conteúdos desses saberes estão interligados com a formação preconizada pela OCDE, para quem, “[...] aparentemente, a ideia central do novo paradigma escolar é atraente e justa: o indivíduo aprende durante toda a vida. O que pressupõe disponibilizar percursos de aprendizagem continuada [...]" (LAVAL, 2019, p. 71); ou seja, o leque dessas pedagogias tem como questão central o desenvolvimento das competências e habilidades que formará o trabalhador no âmbito da escola, para adaptação das novas modalidades dos empregos formais e informais, já que se pressupõe com essa lógica o profissional empreendedor, multifuncional e polivalente.

Do que se pode depreender dessa lógica é o poder decisivo dos organismos internacionais em criar categorias de regulação para o trabalho humano enquanto condição para sua existência social, articuladas às competências e habilidades apreendidas no âmbito da escola, tornando, assim, o trabalho do professor como principal vetor desse ideário facilitador do conhecimento e mediador da paz universal, de acordo com o manual proposto. "Trata-se de inculcar um espírito de empresa que um relatório da OCDE define como

\begin{tabular}{l|l|l|l|l|l} 
(C) Rev. HISTEDBR On-line & Campinas, SP & v.21 & $1-22$ & $\mathrm{e} 021015$ & 2021 \\
\hline
\end{tabular}




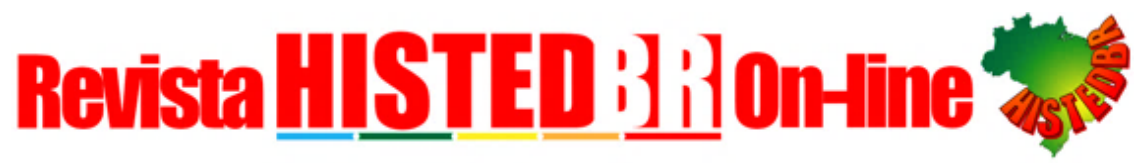

ARTIGO

aquisição de certas disposições e competências do indivíduo: criatividade, iniciativa, aptidão para resolução de problemas, flexibilidade, capacidade de adaptação.” (LAVAL, 2019, p. 79).

O caráter ideológico das orientações prima pelo esforço pessoal, seja do aluno, seja do professor em sala de aula, e através da qualificação profissional instrumentalizada por competências para adaptação das exigências do mundo do trabalho, desdobrando na formação prática de sala de aula por meio de conteúdos curriculares, em realizar aprendizagens significativas por si mesmo. "Esse é o significado do lema 'aprender a aprender', que já nasceu com o pragmatismo por meio do escolanovismo e que se manifesta tão caro às pedagogias das competências.” (RAMOS, 2011, p. 58).

No Brasil, as questões supracitadas repercutiram nos Governos Fernando Henrique Cardoso (1995-2002), com a "Reforma do Estado e a implantação de políticas econômicas e educacionais a partir do discurso de modernização como condição de sua inserção na globalização econômica [...]", como argumenta Oliveira (2009, p. 242). As reformas buscaram consolidar a figura de um "Estado gerencial, no qual a gestão dos sistemas educacionais e das instituições de ensino foi reconhecida como central para melhoria da qualidade do ensino." (FERREIRA, 2009, p. 256).

Com a reforma do aparelho administrativo do Estado brasileiro, a educação tornouse um serviço não exclusivo do Estado, constituindo-se na base física e política uma série de regulações que sucederam as políticas educacionais. O ideário neoliberal, além de subordinar a educação às regras do mercado, direcionou as políticas de reformas educacionais, implantaram programas de formação inicial e continuada de professores, sistema de avaliações externas, ranqueamento das escolas, reformas curriculares e, sobretudo, responsabilização dos trabalhadores docentes pelos resultados quantitativos das avaliações, em uma escala sem precedente no decorrer de toda a história da Educação.

Tais questões foram reafirmadas com aprovação da nova Lei de Diretrizes e Bases da Educação (LDB/Lei n ${ }^{\circ}$ 9.394/96), nos arts. 62, 63, 67e 87, que discorrem sobre a formação de docentes para atuar na educação básica em nível superior, bem como as instituições formativas que deverão manter programas de formação continuada para os profissionais de educação dos diversos níveis de ensino.

Para o exercício do magistério, admitiu-se, na mesma Lei, a qualificação mínima de ensino médio completo, para atuação na docência na Educação Infantil e nas quatro séries do Ensino Fundamental, sustentando, assim, a articulação da formação com requisitos mínimos e operantes, através dos cursos de treinamentos para formação continuada em serviço, como já prevista pelas orientações dos organismos internacionais, na Declaração de Nova Délhi, quando assinalou que "[...] a melhoraria da qualidade e relevância da educação básica seria através dos esforços para aperfeiçoar o 'status', o treinamento e as condições de trabalho do magistério.” (UNESCO, 1993, p. 1). 


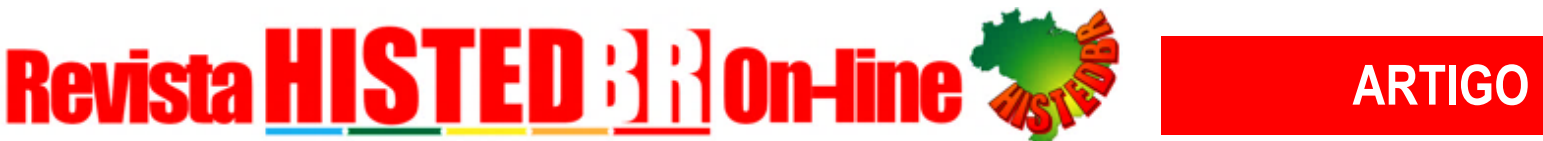

Na verdade, as indicações de Jomtien "[...] podiam ser identificadas nos anteprojetos da LBD que tramitaram durante oito anos no Congresso Nacional, anunciando os cortes de verbas e privatizações que assombrariam a educação nos anos subsequentes." (SHIROMA; MORAES; EVANGELISTA, 2011, p. 52). Toda essa estruturação no campo jurídico foi organizada para responder ao compromisso ideológico firmado durante as Conferências, e tinha como principal articulador financeiro o BM (BANCO MUNDIAL, 1995a, p. 12), que primava pela eficácia na gestão pública, pois "[...] a ineficiência e falta de equidade das despesas públicas na educação aumentaram as despesas públicas em educação.”

A prioridade do BM era destinar investimento para educação básica, recomendando um tipo de formação, multifuncional e técnica, primando por uma formação mínima. Com estas indicações, verifica-se a estruturação da formação inicial e continuada de professores que atuam na alfabetização, mediadas, primeiro, pela concepção das reformas de custos benefícios, segundo, pelo teor assumido dentro das novas concepções de ensinar, inspiradas em técnicas e saberes da prática, para solucionar os problemas referentes à evasão escolar, repetência que assolavam a educação, em específico nas séries iniciais, no processo de alfabetização.

De acordo com o Relatório lançado pelo MEC, denominado de Políticas de melhorias de qualidade da educação - um balanço institucional (2002),

No período compreendido entre os anos de 1995 e 1998, a prioridade do Ministério da Educação foi o segmento do Ensino Fundamental, para o qual foram elaborados diretrizes, parâmetros curriculares e referenciais de formação de professores. De 1999 a 2002, direcionaram-se esforços para a formação de professores, o que significou repensar os cursos de formação inicial e os investimentos em ações de formação continuada, objetivando o aprimoramento da prática dos professores em exercício. (BRASIL, 2002, p. 26).

É nesse contexto que se identifica o preâmbulo do professor-alfabetizador no Brasil, inicialmente, pelo Parâmetro em Ação, em 1998, que trazia um módulo sobre a Alfabetização com 32 horas; o Programa de Alfabetização (PROFA), formulado em 2000, destinado a professores da Educação Infantil, séries iniciais do Ensino Fundamental, e na Educação de Jovens e Adultos (EJA) e possuía carga horária de 160 horas, com orientações metodológicas e coletânea de textos; vídeos com 30 programas em três módulos.

As novas ações governamentais destinadas para alfabetização foram criadas durante os Governos Luís Inácio Lula da Silva (2003-2010); e no ano de 2003, foi lançado "A Década das Nações Unidas para a Alfabetização" (2003-2012); e o Brasil, como um dos membros engajados da UNESCO, tinha o compromisso de cumprir com a agenda internacional acerca da melhoria do índice de alfabetização.

\section{A REGULAÇÃO DO PROFESSOR ALFABETIZADOR NO BRASIL}




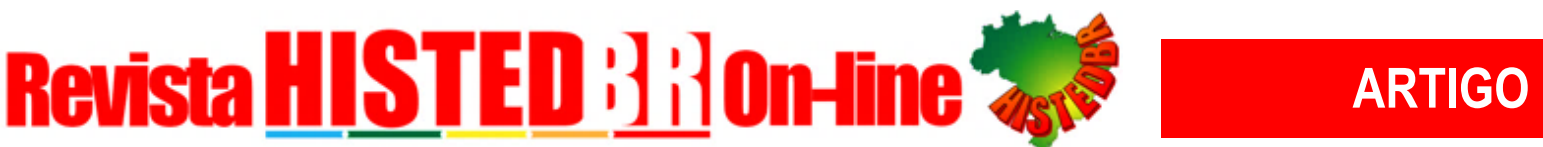

Verifica-se, segundo Gontijo (2014), que o Governo Lula começou com a apresentação do Relatório Final do Grupo de Trabalho (GT), denominado "Alfabetização infantil: novos caminhos", no ano de 2003, que apresentava como conclusão as seguintes afirmações:

\begin{abstract}
Dentre os graves problemas que afetam a qualidade da educação no Brasil, nenhum é maior do que o da alfabetização das crianças. Sem ele, todos os atuais esforços para debelar o analfabetismo adulto estarão condenados ao fracasso, já que o sistema educacional continuará produzindo milhões de brasileiros sem condições de compreender o que leem. [...] Os autores não brasileiros já enfrentaram problemas semelhantes em seus países, mas alertam que seria um grave equívoco reduzir a discussão desta questão a um problema ideológico de direita ou esquerda, de política partidária ou de supostos interesses de mesquinhos editores de livros. (BRASIL, 2007c, p. 164).
\end{abstract}

Os autores do GT recomendavam no Relatório que "[...] as agências bilaterais e multilaterais de investimento, voltadas para os interesses da educação e da criança, poderiam ter um papel fundamental na consolidação dessas iniciativas." (BRASIL, 2007c, p. 164). O GT confrontava a realidade nacional dos problemas com as internacionais, argumentando que "[...] países como Estados Unidos e Inglaterra têm-se baseado nos resultados das avaliações e nas medidas corretivas nelas assentadas para lograr importantes melhorias no desempenho de seus alunos na alfabetização.” (BRASIL, 2007c, p. 156-157).

A busca por novas estratégias para solucionar as questões referentes às problemáticas ao processo de alfabetização se dará com a aprovação da Portaria do MEC de $\mathrm{n}^{\circ} 1.179$, de 06 de maio de 2004, que instituiu o Sistema Nacional de Formação Continuada de Professores da Educação Básica, em parceria com as universidades públicas, e foi determinado, no art. $3^{\circ}$, “[...] o atendimento às necessidades de formação continuada dos professores das séries ou ciclos iniciais do ensino fundamental, em exercício nos sistemas oficiais de ensino dos estados e municípios." (BRASIL, 2004b).

Ressalta-se que a parceria entre o MEC e as universidades, para a formação continuada de professores, segue uma tendência internacional, em conformidade com as mudanças no modo de produção econômica e as necessidades de reconfiguração da formação de professores por meio das reformas políticas instituídas em países como a França, Inglaterra e na América Latina, em específico no Brasil. Segundo o estudo de Foerst (2005, p. 88), “[...] na França, Quebec, Canadá são observadas algumas especificidades que se reportam à própria história a formação de professores desses contextos, mas a emergência da parceria nessa área se assemelha em muitos aspectos às polêmicas sobre reformas educacionais $[\ldots] "$ ".

Essas polêmicas evidenciam, segundo seus defensores, que os professores possuem conhecimentos acumulados e não sabem como dispor deles, pois não estão articulados com a prática, e a universidade acaba sendo acusada de não promover a formação inicial para o trabalho pedagógico com a escola básica. O movimento teórico pautado na epistemologia da 


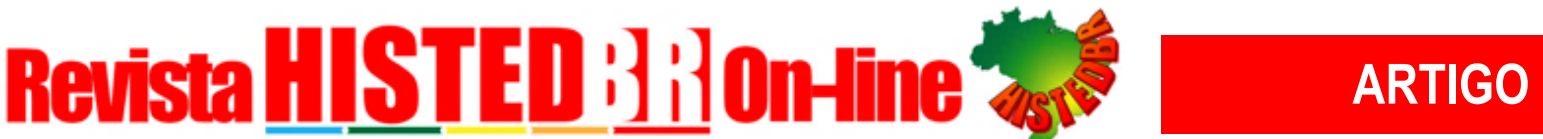

prática, influenciada em autores como Schön (1992), compreende a formação de professores a partir da ação reflexiva e construção de saberes e competências.

Desse modo, a tendência crítico-reflexiva tornou-se a concepção oficial de formação continuada de professores, e foi sendo absorvida dentro das universidades, que vêm fundamentando a formação continuada de professores dos programas oficiais de alfabetização, a exemplo do Programa Pró-Letramento (BRASIL, 2008a), que visava a melhoria da qualidade de aprendizagem da leitura/escrita e matemática nos anos/séries iniciais do Ensino Fundamental, destinados a todos os professores em serviços atuantes das séries iniciais. De acordo com Gontijo (2014, p. 68), “[...] o programa se inseriu no âmbito da formação para atendimento dos problemas referentes ao desempenho em Língua Portuguesa e Matemática apontada pelos resultados do Sistema de Avaliação da Educação Básica (SAEB).”

Registra-se que o redirecionamento das políticas educacionais dos Governos Lula para reorganização da escola básica alterou significativamente os níveis de organização das séries iniciais na legislação já existente, como a LDB n ${ }^{0}$ 9.394/96, por exemplo, a implantação da escola de nove anos e outros instrumentos normativos para educação, nos quais um dos focos dessa mudança foi o processo de alfabetização das séries iniciais.

O documento denominado de "Ensino Fundamental de nove anos: orientações gerais" aponta o porquê da necessidade de reorganização da estrutura da escola a partir dos seguintes argumentos:

Conforme recentes pesquisas, $81,7 \%$ das crianças de seis anos estão na escola, sendo que 38,9\% frequentam a Educação Infantil, 13,6\% as classes de alfabetização e 29,6\% já estão no Ensino Fundamental (IBGE, Censo Demográfico 2000). Esse dado reforça o propósito de ampliação do Ensino Fundamental para nove anos, uma vez que permite aumentar o número de crianças incluídas no sistema educacional. Os setores populares deverão ser os mais beneficiados, uma vez que as crianças de seis anos da classe média e alta já se encontram majoritariamente incorporadas ao sistema de ensino - na pré-escola ou na primeira série do Ensino Fundamental. (BRASIL, 2004a).

O Documento analisado propõe mudanças questionando a estrutura espacial da escola, os currículos e programas escolares, o tempo escolar, destacando "[...] a necessidade de debater com a sociedade outro conceito de currículo e escola com novos parâmetros de qualidade." (BRASIL, 2004a, p. 11). E recomendou ainda que as escolas devessem "investir na criação de um ambiente alfabetizador", a fim de realizarem um trabalho coletivo para reorganização do trabalho pedagógico, além da formação continuada de professores, considerada “[...] uma atitude gerencial indispensável para o desenvolvimento de um trabalho pedagógico qualitativo que efetivamente promova a aprendizagem dos alunos." (BRASIL, 2004a, p. 22-26). 


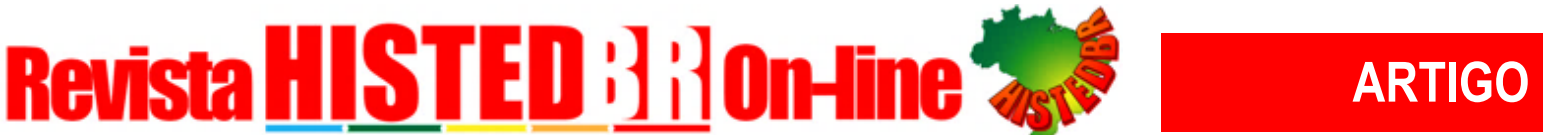

Essa mudança preconizada pelo MEC (BRASIL, 2004a) se materializou após a aprovação da Lei ${ }^{0}$ 11.274/2006, que alterou a LDB de 1996, no art. 32, estabelecendo nova redação, determinando a obrigatoriedade do Ensino Fundamental com duração de 9 (nove) anos, devendo seu início dar-se aos 6 (seis), permanecendo, no inciso I, a orientação do “[...] desenvolvimento da capacidade de aprender, tendo como meios básicos o pleno domínio da leitura, da escrita e do cálculo". Posteriormente, foi aprovado o Parecer CNE/CEB n 4/2008, o qual trouxe definidas as seguintes proposições:

a) $\mathrm{O}$ antigo terceiro período da Pré-Escola não pode se confundir com o primeiro ano do Ensino Fundamental, pois esse primeiro ano é agora parte integrante de um ciclo de três anos de duração, que poderíamos denominar de "ciclo da infância". b) o sistema de ensino ou a escola, desde que goze desta autonomia, faça a opção pelo sistema seriado, há necessidade de se considerar esses três anos iniciais como um bloco pedagógico ou ciclo sequencial de ensino. c) entende-se que a alfabetização dar-se-á nos três anos iniciais do Ensino Fundamental. (BRASIL, 2008b).

Estabelecida essa normatização que evidenciava o processo de constituição da necessidade de alfabetização nas séries iniciais, a gestão do Governo Lula lançou o Plano de Desenvolvimento da Educação (PDE), que trazia no seu bojo mais de 40 programas, entre eles estava contido o processo avaliação do rendimento dos alunos através da Prova Brasil (IDEB), a capacitação de professores, o Fundo de Manutenção e Desenvolvimento da Educação Básica e de Valorização dos Profissionais da Educação (FUNDEB) e o Plano de Ações Articuladas (PAR), que se conformou como um instrumento para melhoria da qualidade da educação do País. (BRASIL, 2007c).

Naquele cenário, o Sistema de Avaliação da Educação Básica (SAEB), criado em 1990, sofreu modificação, com criação da Prova Brasil, cuja “[...] ideia era combinar os resultados de desempenho escolar (Prova Brasil) e os resultados de rendimento escolar (fluxo apurado pelo censo escolar) num único indicador de qualidade: o Índice de Desenvolvimento da Educação Básica (IDEB).” (BRASIL, 2007c, p. 21).

Para garantir a participação dos municípios, foi criado um novo regime de colaboração, tendo como "[...] instrumento jurídico para a concretização desse novo regime é Plano de ações Articuladas (PAR) [...]" (FERREIRA, 2009, p. 262), no qual a garantia da participação dos municípios era assinar o termo de adesão denominado de "Compromisso Todos pela Educação", constituído pelo Decreto de n. ${ }^{\circ}$ 6.094/2007, que dispunha sobre a implantação do Plano de Metas "Compromisso Todos pela Educação," através da União, em regime de colaboração com Municípios, Distrito Federal, Estados e a participação das famílias, comunidades, mediante programas e ações de assistência técnica e financeira para melhoria da qualidade da educação básica. (BRASIL, 2007b).

O referido Decreto tinha 28 diretrizes no Capítulo I, que em síntese se tratava do acesso e a permanência dos alunos na escola, organização do trabalho pedagógico, a formação e a carreira dos profissionais da educação, a gestão da escola e das redes de ensino 


\section{Revista HISTED : Hilon onine}

e valorização dos profissionais da educação. Em relação ao processo de alfabetização, determinaram, no art. $2^{\circ}$, as seguintes diretrizes:

I - estabelecer como foco a aprendizagem, apontando resultados concretos a atingir; II - alfabetizar as crianças até, no máximo, os oito anos de idade, aferindo os resultados por exame periódico específico; III - acompanhar cada aluno da rede individualmente, mediante registro da sua frequência e do seu desempenho em avaliações, que devem ser realizadas periodicamente; IV - combater a repetência, dadas as especificidades de cada rede, pela adoção de práticas como aulas de reforço no contra turno, estudos de recuperação e progressão parcial; [...]. (BRASIL, 2007b, p. 1).

Esse Decreto, além de dispor sobre a nova regulação do processo de alfabetização, juntamente com o PAR, estabeleceu, no art. $3^{\circ}$, que a qualidade da educação básica seria medida, objetivamente, "[...] com base no IDEB, calculado e divulgado periodicamente pelo INEP, Sistema de Avaliação da Educação Básica (SAEB), composto pela Avaliação Nacional da Educação Básica (ANEB) e a Avaliação Nacional do Rendimento Escolar (Prova Brasil)." (BRASIL, 2007d, p. 1). Com isso, “[...] os municípios assumem o compromisso de melhoria da qualidade da educação básica, e o IDEB é o indicador para a verificação do cumprimento de metas fixadas no termo de adesão do compromisso." (FERREIRA, 2009, p. 262).

A operacionalização da Provinha Brasil para alfabetização foi instituída pelo INEP por meio da Portaria Normativa ${ }^{\circ} 10$, de 26 de abril de 2007, com os seguintes objetivos:

i) avaliar o nível de alfabetização dos educandos nos anos iniciais do ensino fundamental;

ii) oferecer às redes de ensino um resultado da qualidade da alfabetização, prevenindo assim o diagnóstico tardio dos déficits de letramento;

iii) contribuir para a melhoria da qualidade do ensino e para a redução das desigualdades, em consonância com as metas e políticas estabelecidas pelas diretrizes da educação nacional. (BRASIL, 2007d, p. 8).

A Provinha Brasil, embora não direcionasse a formação de professores, constituiu-se como um processo de regulação orientada pelas políticas internacionais, primeiro, porque avalia área do conhecimento específica, segundo, porque o desenvolvimento de atividades e a reorganização da prática pedagógica dessas áreas de conhecimento, prevista pela Portaria, é uma forma de gerenciamento pelo MEC dos possíveis resultados ou avanços dos alunos nos processos de leitura.

Destaca-se que a trajetória normativa destinada para solucionar os problemas na alfabetização se complementa com a aprovação da Nova Diretriz Curricular para educação de nove anos, através da Resolução de $n^{\circ} 7 / 2010$, na qual apresentou como articulação e continuidade da trajetória escolar o processo contínuo de aprendizagem, assegurando, no art. 30, as seguintes proposições: 


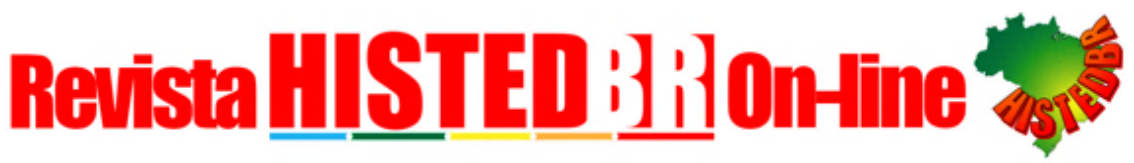

ARTIGO

I - a alfabetização e o letramento;

III - a continuidade da aprendizagem, tendo em conta a complexidade do processo de alfabetização e os prejuízos que a repetência pode causar no Ensino Fundamental como um todo e, particularmente, na passagem do primeiro para $o$ segundo ano de escolaridade e deste para o terceiro.

$\S 1^{\circ}$ Mesmo quando o sistema de ensino ou a escola, no uso de sua autonomia, fizerem opção pelo regime seriado, será necessário considerar os três anos iniciais do Ensino Fundamental como um bloco pedagógico ou um ciclo sequencial não passível de interrupção, voltado para ampliar a todos os alunos as oportunidades de sistematização e aprofundamento das aprendizagens básicas, imprescindíveis para o prosseguimento dos estudos. (BRASIL, 2010, p. 8).

O conjunto normativo apresentado no documento das Diretrizes reproduziu elementos da política anterior, regulamentando a alfabetização na perspectiva do letramento, e incluiu o processo de automação nos três anos iniciais; ou seja, nas três primeiras séries, ou bloco de alfabetização, os alunos não teriam sua sequência interrompida por meio da reprovação, e essa lógica traduzia, na prática, a necessidade de reverter os danos causados nas séries iniciais, que, segundo este entendimento, era causadora do fracasso escolar nos anos iniciais em virtude do processo de reprovação, que incluía, posteriormente, o processo de avaliação do Ciclo de Alfabetização.

Verifica-se que no ano de 2010 estava encerrada a gestão do Governo Lula e iniciava a gestão do Governo Dilma Rousseff (2011- ago. 2016), e no ano de 2012 encerrava-se "A Década das Nações Unidas para Alfabetização: Educação para Todos”, iniciada em 2003. Nota-se que todo o movimento feito dentro do conjunto de leis e diretrizes apresentado na gestão do Governo Lula projetou para a regulação das políticas educativas e a implementação de mais um programa de formação denominado de Pacto Nacional pela Alfabetização na Idade Certa (PNAIC) (2012-2017), compreendido, neste estudo, como a reprogramação da formação continuada de professores alfabetizadores.

A reprogramação do PNAIC na gestão do Governo Dilma, por intermédio da Portaria de $n^{\circ} 867$, de 4 de julho de 2012, dar-se-á pela incorporação de elementos teóricos já instituídos nos programas anteriores de formação continuada de professores alfabetizadores, quando o então ministro da Educação, Aloízio Mercadante, reafirma e amplia o compromisso assumido no Decreto $n^{\circ}$ 6.094/2007, que dispõe sobre a implementação do Plano de Metas “Compromisso Todos pela Educação".

Configurou-se, segundo o documento Manual do pacto: Pacto pela Alfabetização na Idade Certa: o Brasil do futuro com o começo que ele merece,

[...] que o PNAIC é um compromisso assumido pelo governo federal, do Distrito Federal, dos Estados e Municípios para assegurar que todas as crianças estejam alfabetizadas até os 8 anos de idade, ao final do $3^{\circ}$ ano do ensino fundamental". (BRASIL, 2012, p. 11). No referido documento, foi proposto que, entre os compromissos dos municípios que teriam aderido ao Pacto era alfabetizar todas as crianças em língua portuguesa e em 


\section{RevistaHIISTED Bition Hine ARTico}

matemática; realizar avaliações anuais universais [...]. (BRASIL, 2012, p. $11)$.

Diferentemente dos programas anteriores, PROFA (BRASIL, 2001), Pró-Letramento (BRASIL, 2008a), o PNAIC (BRASIL, 2012), por meio de sua Portaria, reprograma o processo de alfabetização para as séries iniciais, incorporando elementos já produzidos nos programas anteriores, ampliando o processo quantitativo por meio de avaliações externas para os alunos em aprendizagem específica, de Língua Portuguesa e Matemática, ganhando espaço nas instituições a tríade do ideário da pedagogia da competência, em que os professores se propõem a organizar o trabalho pedagógico, definir as estratégias de ensino e encaminhar o processo de avaliação externa.

Segundo as informações apresentadas no Planalto no lançamento do PACTO (BRASIL, 2012), ainda estavam latentes os índices de alfabetização no País, quando o IBGE (2010) fazia a simples pergunta sobre a habilidade de ler e escrever para crianças de 10 anos de idade. Os resultados acerca da leitura e escrita foram positivos e negativos em diferentes estados, destacando as regiões Norte e Nordeste, com números que representavam o resultado das políticas, econômicas regionais, com séculos de atraso para a universalização da educação básica. Em relação às crianças de 10 anos de idade, que precisariam dominar a leitura e a escrita, verifica que:

[...] os estados do Norte e Nordeste apresentavam números bastantes elevados, o estado do Pará aparecia com 14,6 \%, o estado do Maranhão com 16,4\%, o estado de Alagoas apresentava 17,8 \%. Os números indicavam a necessidade de pensar políticas que tivessem como prioridade resolver o problema detectado nas séries iniciais. (IBGE, 2010, p. 63-64).

Mesmo com a adoção do conceito de "alfabetização funcional", introduzido pela UNESCO no final dos anos de 1950, que passou a denominar uma pessoa alfabetizada, ou seja, aquela que fosse capaz de ler, escrever e compreender um pronunciado simples do cotidiano (GONTIJO, 2014), verifica que em 2010 " [...] o País contava com 9,6\% da população de 15 anos ou mais de idade analfabeta, o que corresponde a 13.933. 173 pessoas que não sabiam ler e escrever [...]”. (IBGE, 2010, p. 60).

Portanto, na sua forma aparente, o PNAIC (BRASIL, 2012) foi apresentado como um programa reprogramado, contendo um conjunto de orientações pedagógicas, materiais e referências curriculares pedagógicas projetadas pelo MEC em parceria com as universidades, com a finalidade de contribuir para o avanço do processo de alfabetização e letramento. Os objetivos do Programa foi estabelecido no art. $5^{\circ}$, Portaria $n^{\circ} 867$, de 4 de julho de 2012, que determinava:

I- garantia de que todos os estudantes dos sistemas públicos de ensino estejam alfabetizados, em Língua Portuguesa e em Matemática, até o final do $3^{\circ}$ ano do ensino fundamental;

II - reduzir a distorção idade-série na Educação Básica;

III - melhorar o Índice de Desenvolvimento da Educação Básica (IDEB); 


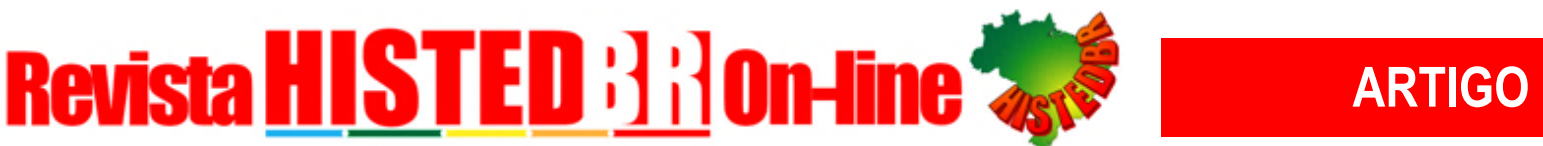

IV - contribuir para o aperfeiçoamento da formação dos professores alfabetizadores;

V - construir propostas para a definição dos direitos de aprendizagem e desenvolvimento das crianças nos três primeiros anos do ensino fundamental. (BRASIL, 2012).

Verifica-se uma relação de quase "terminalidade" do processo de alfabetização, no inciso I: "[...] garantia de que todos os estudantes dos sistemas públicos de ensino estejam alfabetizados, em Língua Portuguesa e em Matemática, até o final do $3^{\circ}$ ano do ensino fundamental." (BRASIL, 2012). Essa terminalidade não se reproduz apenas no conjunto de leis, decretos e pareceres da lei brasileira; tem relação direta com as orientações internacionais, já mencionadas anteriormente, quando anunciam a garantia da equidade social através de políticas focalizadas e direcionadas para a formação continuada do professor e sua aplicação diretamente na escola.

A avaliação da aprendizagem prevista no inciso III dessa Portaria, para "[...] melhorar o Índice de Desenvolvimento da Educação Básica (IDEB) [...]” (BRASIL, 2012), considerada pela política governamental como elemento central para garantia do processo de alfabetização nas séries iniciais, bem como a qualidade da educação, foi reproduzida, na prática, pelo instrumento denominado de Avaliação Nacional da Alfabetização (ANA), com os seguintes objetivos:

i) Avaliar o nível de alfabetização dos educandos no $3^{\circ}$ ano do ensino fundamental.

ii) Produzir indicadores sobre as condições de oferta de ensino.

iii) Concorrer para a melhoria da qualidade do ensino e redução das desigualdades, em consonância com as metas e políticas estabelecidas pelas diretrizes da educação nacional. (BRASIL, 2013, p. 7).

Esse processo avaliativo, introduzido na gestão da alfabetização, tornou-se uma ferramenta de regulação do conhecimento pelo Estado, pois visava medir os avanços das práticas do fazer do professor, produzindo também ilusões acerca da garantia dos direitos de aprendizagens, quando na verdade reproduziu a regulação do trabalho docente e a responsabilização pelo insucesso dos programas implementados. A vinculação da formação continuada de professores alfabetizadores à lógica do desempenho gera mais especulação do que propriamente resultado, como mostra o Relatório da prova ANA (BRASIL, 2018, p. 74 75):

A maior concentração de estudantes, no âmbito nacional, se dá nos Níveis 2 e 3 da escala de Leitura (33\% e 32\%, respectivamente). No Nível 2, os itens passam a exigir compreensão de textos simples, considerando as características do gênero, e o resgate de informações contidas nele, principalmente no título ou na frase inicial. Já no Nível 3, além da compreensão geral de textos mais longos e complexos, constam também habilidades que requerem relacionar várias informações contidas no texto em um maior nível inferencial, tais como inferir sentido de expressão ou palavras e assunto em textos verbais e não verbais. [...] A maior concentração de estudantes brasileiros está no Nível 4 da escala de Escrita 


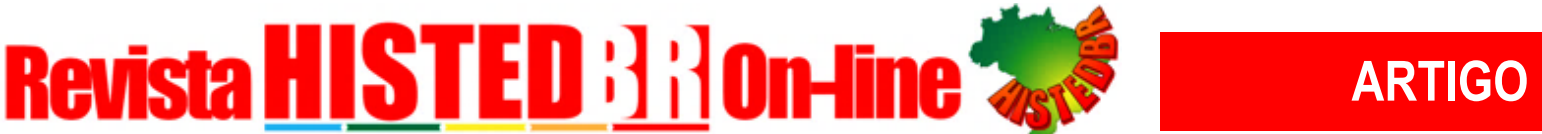

(58\%). Neste nível os estudantes provavelmente escrevem as palavras apresentadas corretamente, independentemente de sua complexidade, e atendem à proposta de construir uma narrativa, embora ainda possam incorrer em desvios que comprometem parcialmente o sentido desta. Esse cenário é replicado em todas as regiões (44\% no Norte; $46 \%$ no Nordeste; $62 \%$ no Centro-Oeste; $66 \%$ no Sudeste e $68 \%$ no Sul).

Esses resultados demostram duas questões para se pensar. A primeira é que os "artifícios" direcionados pelo PNAIC para a formação continuada do professor alfabetizador, com a perspectiva de resolver o problema do déficit da educação brasileira através do processo do controle e da regulação a partir da avaliação externa, não repercutiram em resultados qualitativos. Na segunda questão, a regulação da alfabetização, por meio da avaliação das crianças, apenas mudou o foco da reprovação para o final do terceiro ano, que antes acontecia no final do primeiro ano, pois, consequentemente, grande parte dessas crianças no âmbito escolar ficará retida porque não se apropriaram da escrita ou da leitura de maneira determinada no final do terceiro ano.

Embora essa terminalidade tenha sido reafirmada no Plano Nacional de Educação, Meta 5 - "[...] alfabetizar todas as crianças, no máximo, até o final do $3^{\circ}$ (terceiro) ano do Ensino Fundamental [...]" (BRASIL, 2015, p. 27) -, autores como Gontijo (2014, p. 11) expressam que "[...] mesmo que o acesso à escola tenha sido democratizado em muitas regiões do mundo, a qualidade da educação - e principalmente a da alfabetização - não é suficiente para que se adquiram condições para continuar aprendendo."

A grande questão é pensar se algumas dessas capacidades são possíveis de serem alcançadas dentro de uma terminalidade. $\mathrm{O}$ que fazer com os alunos que não desenvolvem todas as exigências? Somado a esse contexto, ainda existe a particularidade da formação continuada de professores alfabetizadores, que pressupõem que o trabalho docente produzirá resultados positivos, pois a sua participação durante o aperfeiçoamento, realizada mensalmente, objetivou o desenvolvimento das capacidades de alfabetizar de acordo com os parâmetros propostos.

Embora haja conformidade da legitimidade do PNAIC e dos referenciais teóricos de composição dos documentos que orientam a formação continuada de professores alfabetizadores, é preciso vislumbrar a inserção da lógica dos documentos multilaterais reproduzidos pelos documentos de formação, que seguem uma lógica abstrata de caráter especulativo e privilegiam aprendizagens específicas; e sendo justificadas tais ingerências, mediante as diversas concepções pedagógicas e novos conhecimentos dos alunos no início da escolarização, pautada na avaliação externa e nas práticas reflexivas, pode comprometer o processo de construção de conhecimento historicamente construído pelas diversas gerações. 


\section{RevistaHIISTED BifilOn-Hine ARTICo}

\section{CONSIDERAÇÕES FINAIS}

As questões apresentadas neste artigo representam algumas considerações acerca da regulação da formação continuada de professores alfabetizadores no Brasil, movimentada de acordo com as orientações dos organismos internacionais e articuladas às políticas de formação inicial e continuada de professores e avaliação externa. Demarcada pelo "divórcio" entre uma formação sólida e as exigências do Estado para contenção de gastos públicos, programou-se ações estratégicas e fabricou-se, de forma consensual, a ideia de que o País vem investindo em formação de professores desde o Governo FHC, com as políticas curriculares, PCN, PCN em Ação, e, posteriormente, implementação de programas como o PROFA (BRASIL, 2001), Pró-Letramento (BRASIL, 2008), dentre outros praticados até o ano de 2013, com a implementação do PNAIC.

Dessa lógica econômica, estabeleceu-se a formação de professores no Brasil, fazendo valer como leis gerais e abstratas o espontaneísmo teórico da formação, concebida a partir de aprendizagens sistematizadas por grupos de intelectuais que negam a importância da formação de professores em uma perspectiva teórica e prática a longo prazo. A julgar pelo exposto na literatura aqui reunida, todo o esforço constituído para a formulação da política de formação continuada de professores alfabetizadores no Brasil está articulado à tríade formação continuada de professores, alfabetizadores-conhecimentos específicos de língua portuguesa-matemática e avaliação externa, que, regulada com um conjunto de ações executada no País foram sendo recriadas outras estratégias, na medida em que os resultados das avaliações externas das classes de alfabetização não deram o retorno esperado.

Nesse sentido, a formação continuada de professores alfabetizadores encaminha-se para o esvaziamento da educação e formação humana, destituída de qualquer sentido crítico e pautada na lógica do conhecimento reduzido e da necessidade de revitalizar novos projetos de alfabetização de caráter cada vez mais excludentes, tais como a normatização da nova política de alfabetização e a Base Curricular Nacional (BNCC), que propõem processos de experimentação na busca por resultados operacionais por meio da avaliação periódica para todos os estudantes matriculados no final do $2^{\circ}$ ano, considerado como o novo prazo de a criança apropriar-se da leitura e da escrita e do cálculo.

Conclui-se esta pesquisa reafirmando a necessidade de uma formação continuada de professores alfabetizadores estruturada em torno de perspectiva teórica que promova a superação de práticas pedagógicas guiadas por um senso comum e esteja comprometida com a ampliação das máximas possiblidades de formação, tencionando, assim, para mudanças no processo de alfabetização das crianças e no processo de qualificação docente, considerando o conhecimento científico fundamental para o desenvolvimento do trabalho educativo. 


\section{RevistaHIISTED ijilOn Hine ARTICo}

AUTORIA:

* Mestrado em Educação pela Universidade Federal do Pará (UFPA). Professora adjunta I no Curso de Pedagogia da Universidade Federal do Pará (UFPA), Campus Universitário do Marajó/Breves. Contato: solangesilva@ufpa.br

COMO CITAR ABNT:

SILVA, S. P. da. A regulação da formação continuada de professores alfabetizadores no Brasil.

Revista HISTEDBR On-line, v. 21, p. 1-22, abr. 2021. DOI: 10.20396/rho.v21i00.8658491.

Disponível em: https://periodicos.sbu.unicamp.br/ojs/index.php/histedbr/article/view/8658491.

Acesso em: 3 maio 2021.

\section{Notas}

1 " [...] Essa concepção quer que se admita como evidente que as instituições seja conduzidas pelas demandas individuais e pelas necessidades locais de mão de obra, e não por uma lógica de igualdade, solidariedade ou redistribuição em escala nacional. Nesse novo modelo, a educação é considerada um bem de capitalização privado." (LAVAL, 2019, p. 110). 